\title{
La nueva mujer egipcia y su historia literaria francófona*
}

\author{
Fátima CONTRERAS \\ Universidad de Sevilla \\ fatimaconpe@gmail.com \\ https://orcid.org/oooo-0003-4548-8356
}

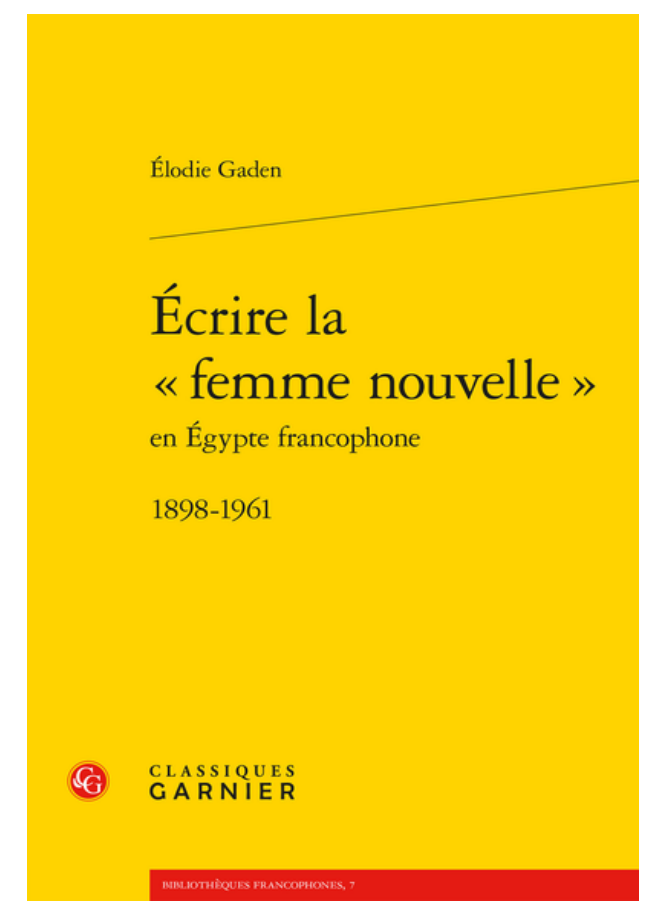

El presente libro constituye una
contribución ineludible para compren-
der la historia literaria de las egipcias
francófonas y las francesas instaladas en
Egipto entre 1898 y 1961 . Esta comuni-
dad de escritoras se propuso crear sus
propias representaciones de Oriente sin
caer en estereotipos, prejuicios o tópicos
orientalistas de Occidente. La obra
surge de los temas tratados en la tesis
doctoral de la autora, Élodie Gaden, que
fue premiada en la Universidad Greno-
ble Alpes (2014) gracias a su extraordi-
naria labor de investigación. El título
Écrire la «femme nouvelle» en Égypte
francophone. 1898-1961 hace referencia
a la obra del jurista egipcio Qasim Amīn
al-Marra al-Ŷadīda [La nueva mujer]

de 1901. Qasim Amīn (1863-1908) explicaba la sumisión de la mujer a través de la imposición del velo, el matrimonio forzado y la falta de educación. Esta obra causó un enorme impacto y una gran polémica a nivel nacional e internacional. Amīn dedicó la mayor parte de su vida a denunciar la situación de precariedad en cuanto a derechos y deberes de las egipcias y a defender su liberación.

\footnotetext{
* Acerca del libro de Élodie Gaden, Écrire la «femme nouvelle» en Égypte francophone. 1898-1961 (París, Classiques Garnier, 2019, coll. «Bibliothèques francophones» $\mathrm{n}^{0}$ 7, 434 p. ISBN: 978-2-406-07791-6).
} 
La obra comienza con el «Avertissement» sobre el alfabeto y las traducciones. Seguidamente, encontramos una «Introduction» donde la autora presenta los apartados y plantea las cuestiones que abordará en las próximas páginas. Su propósito es desvelar la complejidad y la riqueza de la literatura femenina en Egipto empleando como corpus de trabajo los libros y los artículos periodísticos de las escritoras Jehan d'Ivray, Valentine de Saint-Point, Out-el-Kouloub y Doria Shafik. Para llevar a cabo este análisis, el libro se divide en tres bloques principales.

El primer bloque, «S'exprimer en Égypte quand on est une femme. Enjeux sociaux et linguistique», versa sobre los aspectos sociales y lingüísticos que se desarrollan en torno a la mujer en Egipto desde 1872 hasta 1960. Para ello, es imprescindible contextualizar la evolución de las reivindicaciones que exigían las asociaciones de mujeres. Al calor de los nuevos debates que dominaban la esfera pública egipcia, las mujeres exigían un papel activo en la sociedad. El movimiento feminista egipcio nació como una necesidad de las mujeres por mejorar sus derechos y abolir la dominación masculina.

A continuación, la autora ofrece un análisis de las teorías feministas de jueces islámicos como Qasim Amīn, Mohamed Abduh y Rifa'a al-Tahtawi. Este último se erige en uno de los mayores defensores de la educación de las jóvenes egipcias. Dichos pensadores favorecieron las reformas que impulsaron el estatuto personal de la mujer. Según afirmaban estos juristas, el avance social y político de Egipto dependía del estatus de la mujer. Es decir, solo mejorando los derechos de las mujeres lograrían fundar una nación que avanzara hacia la modernidad.

En el proceso de lectura hemos podido examinar el papel de la lengua francesa dentro de la lucha feminista. Así, en el tercer capítulo «De l'apprentissage du français à la prise de conscience féministe», la autora reflexiona sobre el modelo feminista europeo, así como la influencia de la presencia francesa en Egipto en contextos políticos, religiosos, culturales y sociales. De este modo, encontramos apartados dedicados a ejemplificar la repercusión del uso del francés en la sociedad egipcia: la influencia de las misiones religiosas extranjeras en Egipto, concretamente aquellas enviadas por el gobierno francés; la relación entre el nacionalismo y el concepto de feminismo construido en Egipto; y, por último, el valor de la revista feminista egipcia L'Egyptienne (1925-1940) publicada en francés.

Este volumen pone en evidencia la relevancia del uso del francés como medio de difusión de las actividades emancipadoras que llevaban a cabo las asociaciones de mujeres egipcias, principalmente la UFE (Unión Feminista Egipcia). Su gran labor en la lucha contra el patriarcado fue difundida por Europa, América y otros países árabes. Aunque la visión feminista de la UFE es universalista, aspira a contar con la solidaridad europea e internacional y a beneficiarse de sus logros, no por ello dejan de mostrar una posición autónoma contra los prejuicios europeos y los estereotipos 
orientalistas. En este sentido, destaca la misión de Huda Sha'rawi como pionera de la emancipación femenina utilizando nuevas estrategias como la prensa femenina y feminista, así como los congresos y reuniones que organizaban las asociaciones de mujeres. Su discurso enfatizaba la necesidad de un cambio en la sociedad egipcia donde las mujeres alcanzasen mejores derechos, dentro de una concepción global que abarcaba todos los ámbitos: el cultural, el artístico, el político, el jurídico. Gaden recalca asimismo el trabajo de la socióloga Mansour Fahmy sobre la condición femenina desde la visión islámica, desarrollado en su tesis doctoral dirigida por Lévy Bruhl en 1913 y titulada La Condition de la femme dans la tradition et l'évolution de l'islamisme.

Después del amplio estudio preliminar que hemos abordado, la obra incluye, como segunda parte, un análisis en profundidad de los textos publicados de las cuatro escritoras seleccionadas. En «Les genres à l'oeuvre. Fiction narrative, littérature d'idées et poésie», Élodie Gaden muestra el perfil vital e intelectual de cada escritora. Igualmente, presenta sus discursos de carácter emancipador que contribuyeron a configurar el concepto de mujer moderna e independiente. En ellos supieron expresar con clarividencia intelectual su opinión respecto a las transformaciones que la sociedad egipcia y su sistema patriarcal debían realizar. Gaden organiza este bloque en ocho capítulos donde dedica uno a cada autora, excepto en el caso de Jehan d'Ivray que aporta dos capítulos divididos en dos géneros literarios: la historia y la novela costumbrista. Para terminar el análisis de las autoras, Gaden aporta un capítulo dedicado a sus poemarios publicados. Al igual que el resto de los bloques, la autora completa este con una introducción y una conclusión.

Por un lado, encontramos a Out-el-Kouloub (1899-1968) y a Doria Shafik (1908-1975). Estas activistas forman parte de un grupo selecto de la élite egipcia que, según la tradición islámica, solían ser instruidas en francés dentro de los harenes. Ambas decidieron abandonar el espacio privado del harén para reivindicar su papel dentro de la sociedad egipcia. En la literatura de Out-el-Kouloub destaca su trabajo como ensayista y especialmente la fuerza de su discurso. Gaden centra su análisis en dos de sus obras: $L a$ Nuit de la Destinée (1954) y Harem (1937). Ambas se aproximan al concepto de interculturalidad entre la tradición literaria francesa y egipcia. También es interesante mencionar sus estudios sobre el islam, donde reflexiona sobre el papel de la religión en la modernidad de su país y cómo ello afecta a la mujer. La investigadora finaliza destacando su evolución desde la literatura de ficción hasta la literatura de ideas. El arte y la filosofía son atributos en la redacción de Doria Shafik. Entre 1928 y 1932 debutó en la revista feminista L'Egyptienne como protegida de la activista Huda Sha'rawi. En 1944 se doctoró en filosofía por la Sorbona y presentó dos tesis doctorales: L'art pour l'art dans l'Égypte Antique y La femme et le droit religieux de l'Égypte contemporain. Más tarde, le ofrecieron el puesto de redactora jefe de $L a$ 
Femme Nouvelle, una revista francesa especializada en el ámbito cultural y literario. Tras su éxito, decidió fundar Bint al-Nil, traducido como Las Hijas del Nilo, con el objetivo de educar y difundir las reivindicaciones feministas egipcias. También, dedicó varios años de su carrera a la poesía.

Por otro lado, descubrimos el perfil de Jehan d'Ivray (1861-1940) y de Valentine de Saint (1875-1956). Ambas formaron parte de un amplio número de francesas instaladas en Egipto y colaboradoras en la lucha feminista. Durante su estancia en el norte de Affrica fueron testigos y protagonistas del proceso de emancipación femenino tanto en Europa como en Egipto. En la literatura de Jehan d'Ivray existen numerosas referencias a la novela costumbrista, reflejadas en el análisis de su obra clave Le Prince Mourad. Asimismo, explora los ensayos de género histórico como la llegada de Bonaparte a Egipto; y de carácter religioso, concretamente, los estudios relacionados con el Cardenal Mercier y Saint-Jérôme. En cuanto a Valentine de Saint-Point se centra en el fenómeno nacionalista que sacudió a Egipto y a Siria entre 1924 y 1925. Además, la autora subraya su participación activa en la prensa, en la que destaca la revista Le Phoenix. Su profesión como escritora culmina con el polémico ensayo titulado La Verité sur la Syrie (1929). Por último, se dedicó a la lírica durante sus últimos años.

Se reserva la tercera parte del volumen a la exposición detallada de las autoras desde el ámbito orientalista, que lleva por título «L'Orient des Femmes». Con ello, la autora pretende desvelar, denunciar y combatir el orientalismo latente y los estereotipos sobre las mujeres árabes y musulmanas que dominaban la mentalidad europea de su época. Esta retrospección nutrida por el entorno social llega a ser una característica distintiva en las obras de Doria Shafik. Su experiencia como intelectual árabe en París y su testimonio como periodista en la prensa egipcia revelan su compromiso con la lucha feminista y los prejuicios que sufrió durante sus estancias en el extranjero. Del mismo modo, encontramos los testimonios de Out el-Koutub en su obra Ramza, donde presenta la opresión del patriarcado, la aspiración de Valentine de Saint-Point hacia la unión de civilizaciones, y las reflexiones de Jehan d'Ivray sobre las relaciones interculturales y el imaginario orientalista.

La obra culmina en una conclusión general que entresaca los resultados claves de la investigación. En primer lugar, las escritoras estudiadas aspiraban a crear una literatura sin género, es decir, sin clasificar los géneros literarios según el sexo del autor. En segundo lugar, sus escritos pretenden demostrar que su creación literaria no proviene de un modelo francés ni de la imitación de la literatura francesa. Por último, las autoras no buscan pertenecer a un género literario concreto, sino que sus obras van más allá de las fronteras lingüísticas y culturales. En otras palabras, nunca quedan fijadas por un único principio. No obstante, todas comparten un interés por compartir sus experiencias personales y mostrar su apoyo en a la lucha feminista. Finalmente, el libro incluye en sus últimas páginas un apéndice 
donde ofrece un listado bibliográfico especifico de Jehan d'Ivray, Valentine de Saint-Point, Out-el-Kouloub y Doria Shafik. Además de dos índices de nombres y obras que la autora ha citado a lo largo de su estudio.

En definitiva, el libro aquí reseñado ofrece una amplia perspectiva de la situación lingüística y cultural que vivieron las mujeres egipcias y francesas afincadas en Egipto, y cómo ello repercutió en el movimiento feminista. Así pues, el lector es testigo de la notable aportación de Élodie Gaden, considerando la escasez de investigaciones publicadas que vayan enfocadas a este periodo cultural y social de Francia y Egipto. Con todo, la autora logra visibilizar un capítulo olvidado de la historia literaria e incluso, cuestionar el estatus de la literatura femenina y de la literatura francófona en la tradición egipcia. Para ello, aporta Gaden una metodología actualizada basada en métodos de investigación poscoloniales, culturales y estudios de género. Destaca el amplio corpus seleccionado que abarca artículos y entrevistas en numerosas revistas y periódicos, así como novelas, ensayos y seminarios. Sus reflexiones nos permiten aclarar cuestiones imprescindibles para entender los avances del feminismo egipcio a través de la literatura, las conferencias y la prensa gracias a su gran labor como investigadora.

\section{REFERENCIAS BIBLIOGRÁFICAS}

AMĪN, Qasim (2000 [1901]): La nueva mujer. Traducción de Juan Antonio Pacheco Paniagua. Madrid, Instituto Egipcio de Estudios Islámicos. 